\title{
Diffusion coefficients of organic molecules in sucrose-water solutions and comparison with Stokes-Einstein predictions
}

\author{
Yuri Chenyakin $^{1}$, Dagny A. Ullmann ${ }^{1}$, Erin Evoy ${ }^{1}$, Lindsay Renbaum-Wolff ${ }^{1, a}$, Saeid Kamal ${ }^{1}$, and Allan K. Bertram ${ }^{1}$ \\ ${ }^{1}$ Department of Chemistry, University of British Columbia, Vancouver, BC, V6T 1Z1, Canada \\ ${ }^{a}$ now at: Aerodyne Research, Inc., Billerica, MA 01821, Boston College, Chestnut Hill, MA 02467, USA
}

Correspondence to: Allan K. Bertram (bertram@chem.ubc.ca) and Saeid Kamal (skamal@chem.ubc.ca)

Received: 15 August 2016 - Discussion started: 24 August 2016

Revised: 30 December 2016 - Accepted: 16 January 2017 - Published: 15 February 2017

\begin{abstract}
The diffusion coefficients of organic species in secondary organic aerosol (SOA) particles are needed to predict the growth and reactivity of these particles in the atmosphere. Previously, viscosity measurements, along with the Stokes-Einstein relation, have been used to estimate the diffusion rates of organics within SOA particles or proxies of SOA particles. To test the Stokes-Einstein relation, we have measured the diffusion coefficients of three fluorescent organic dyes (fluorescein, rhodamine $6 \mathrm{G}$ and calcein) within sucrose-water solutions with varying water activity. Sucrose-water solutions were used as a proxy for SOA material found in the atmosphere. Diffusion coefficients were measured using fluorescence recovery after photobleaching. For the three dyes studied, the diffusion coefficients vary by $4-5$ orders of magnitude as the water activity varied from 0.38 to 0.80 , illustrating the sensitivity of the diffusion coefficients to the water content in the matrix. At the lowest water activity studied (0.38), the average diffusion coefficients were $1.9 \times 10^{-13}, 1.5 \times 10^{-14}$ and $7.7 \times 10^{-14} \mathrm{~cm}^{2} \mathrm{~s}^{-1}$ for fluorescein, rhodamine $6 \mathrm{G}$ and calcein, respectively. The measured diffusion coefficients were compared with predictions made using literature viscosities and the Stokes-Einstein relation. We found that at water activity $\geq 0.6$ (which corresponds to a viscosity of $\leq 360 \mathrm{~Pa}$ s and $T_{\mathrm{g}} / T \leq 0.81$ ), predicted diffusion rates agreed with measured diffusion rates within the experimental uncertainty $\left(T_{\mathrm{g}}\right.$ represents the glass transition temperature and $T$ is the temperature of the measurements). When the water activity was 0.38 (which corresponds to a viscosity of $3.3 \times 10^{6} \mathrm{~Pa}$ s and a $T_{\mathrm{g}} / T$ of 0.94$)$, the Stokes-Einstein relation underpredicted the diffusion coefficients of fluorescein, rhodamine $6 \mathrm{G}$ and calcein by a factor of 118 (minimum of 10 and maximum of
\end{abstract}

977), a factor of 17 (minimum of 3 and maximum of 104) and a factor of 70 (minimum of 8 and maximum of 494), respectively. This disagreement is significantly smaller than the disagreement observed when comparing measured and predicted diffusion coefficients of water in sucrose-water mixtures.

\section{Introduction}

Large quantities of volatile organic compounds, such as isoprene, $\alpha$-pinene and toluene, are emitted into the atmosphere annually. Subsequently, these molecules are oxidized in the atmosphere to form semivolatile organic compounds, which can condense to the particle phase and form secondary organic aerosol (SOA). Although the exact chemical composition of SOA is not known, the average oxygen-to-carbon elemental ratio of SOA ranges from approximately 0.2 to 1.0 (Aiken et al., 2008; Chen et al., 2009; DeCarlo et al., 2008; Hawkins et al., 2010; Heald et al., 2010; Jimenez et al., 2009; $\mathrm{Ng}$ et al., 2010; Takahama et al., 2011). Due to the hygroscopic nature of SOA (Hildebrandt Ruiz et al., 2015; Massoli et al., 2010), an important component of SOA particles is water. To emphasize this point, in the following we will refer to these particles as SOA-water particles. As the relative humidity $(\mathrm{RH})$ varies in the atmosphere from low values to $100 \%$, the water content (or water activity, $a_{\mathrm{w}}$ ) of the SOAwater particles will also vary from low values to high values to maintain equilibrium with the gas phase.

In order to predict properties of SOA-water particles, information on the diffusion rates of water, oxidants and organic molecules within these particles is needed. For ex- 
(a)

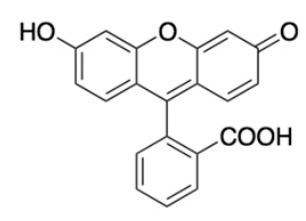

(b)

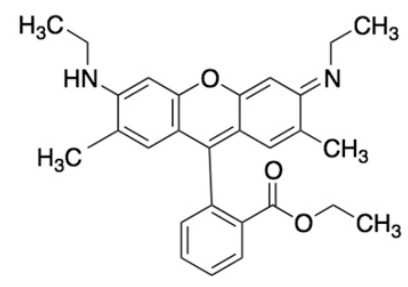

(c)

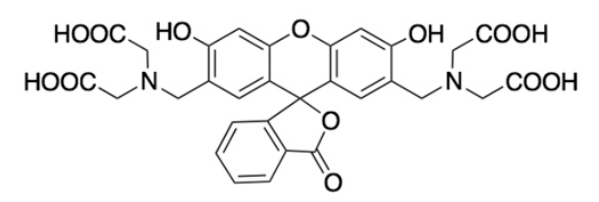

Figure 1. Molecular structures (neutral forms) of the three fluorescent organic dyes used in this work: fluorescein, rhodamine $6 \mathrm{G}$ and calcein.

ample, information on the diffusion of water within SOAwater particles is needed for predicting their cloud condensation abilities and ice nucleating abilities (Adler et al., 2013; Berkemeier et al., 2014; Bones et al., 2012; Lienhard et al., 2015; Price et al., 2015; Schill et al., 2014; Wang et al., 2012; Wilson et al., 2012). Information on the diffusion rates of oxidants and organic molecules is needed for predicting the heterogeneous chemistry and photochemistry of these particles (Davies and Wilson, 2015; Gržinić et al., 2015; Hinks et al., 2016; Houle et al., 2015; Kuwata and Martin, 2012; Li et al., 2015; Lignell et al., 2014; Shiraiwa et al., 2011; Wang et al., 2015; Wong et al., 2015; Zhou et al., 2012). The diffusion rates of organic molecules within SOA-water particles are also needed for predicting the growth rates and size distributions of these particles, as well as the long-range transport of polycyclic aromatic hydrocarbons in the atmosphere (Virtanen et al., 2010; Shiraiwa and Seinfeld, 2012; Shiraiwa et al., 2013; Zaveri et al., 2014; Zelenyuk et al., 2012). Due to the importance of diffusion within SOA-water particles, many studies have recently focused on this topic (e.g. Abramson et al., 2013; Bateman et al., 2016; Kidd et al., 2014; Lu et al., 2014; Marshall et al., 2016; Pajunoja et al., 2014, 2015; Perraud et al., 2012; Robinson et al., 2013; Saleh et al., 2013; Yatavelli et al., 2014; Zhang et al., 2015).

In the following, we focus on the diffusion of organics within SOA-water particles. To predict the diffusion rates of organics within SOA-water particles, some researchers, including ourselves, have used the viscosities of SOA-water particles or proxies of SOA-water particles together with the Stokes-Einstein relation (Booth et al., 2014; Hosny et al., 2013; Koop et al., 2011; Power et al., 2013; Renbaum-Wolff et al., 2013a, b; Shiraiwa et al., 2011; Song et al., 2015, 2016). Given below (Eq. 1) is the Stokes-Einstein relation for the case of no slip at the surface of the diffusing species within a fluid:

$$
D=\frac{k T}{6 \pi \eta R_{\mathrm{H}}},
$$

where $D$ is the diffusion coefficient, $k$ is the Boltzmann constant, $T$ is temperature in Kelvin, $\eta$ is the dynamic viscosity and $R_{\mathrm{H}}$ is the hydrodynamic radius of the diffusing species. Studies are needed to quantify when the Stokes-Einstein relation does and does not provide accurate estimates of the diffusion within SOA-water particles and proxies of SOAwater particles under atmospherically relevant conditions.

Most previous studies that have tested the validity of the Stokes-Einstein equation have used single-component (and often non-polar) matrices (Blackburn et al., 1994, 1996; Chang et al., 1994; Cicerone et al., 1995; Ehlich and Sillescu, 1990; Fujara et al., 1992; Heuberger and Sillescu, 1996; Rossler and Sokolov, 1996; Rossler, 1990). There have also been a few studies (partially motivated by applications in food science) that have tested the validity of the StokesEinstein equation for predicting the diffusion of organics in organic water matrices (Champion et al., 1997; Corti et al., 2008a, b; Rampp et al., 2000; Price et al., 2016). This work has shown that the Stokes-Einstein relation underpredicts the diffusion coefficient of organics in organic water matrices close to the glass transition temperature, although the temperature range over which breakdown occurs is not completely resolved.

Herein, we expand on the previous measurements of the diffusion of organics in organic water matrices. Specifically, we measured the diffusion coefficients of three fluorescent organic dyes within sucrose-water mixtures as a function of $a_{\mathrm{w}}$, and we have compared the measurements with predictions using the Stokes-Einstein relation. Sucrose-water mixtures were used as the matrix in these studies for several reasons: (1) the viscosities of sucrose-water mixtures have been reported for a wide range of atmospherically relevant $a_{\mathrm{w}}$-values; (2) the oxygen-to-carbon ratio of sucrose (0.92) is in the range of $\mathrm{O}: \mathrm{C}$ values observed in oxidized atmospheric particles; and (3) the room temperature viscosities of sucrose-water solutions are similar to the room temperature viscosities of some types of SOA-water particles (compare the viscosities of sucrose-water solutions from Power et al., 2013 with the viscosities of SOA-water particles generated from toluene and photooxidation by Song et al., 2016, isoprene photooxidation by Song et al., 2015 and $\alpha$-pinene ozonolysis by Grayson et al., 2016). The organic dyes chosen for these experiments were fluorescein, rhodamine $6 \mathrm{G}$ and calcein. Shown in Fig. 1 are the structures of these dyes, and Table 1 lists their molecular weight (MW) and hydrodynamic radius $\left(R_{\mathrm{H}}\right)$.

\section{Experimental design}

Rectangular area fluorescence recovery after photobleaching (rFRAP) (Deschout et al., 2010) was used to measure the diffusion coefficients of the fluorescent organic dyes in sucrosewater mixtures. For these experiments, thin films (30-50 $\mu \mathrm{m}$ thick) of sucrose, water and trace amounts of fluorescent dye 
Table 1. The molecular weight (MW) and hydrodynamic radius $\left(R_{\mathrm{H}}\right)$ of the fluorescent organic dyes used in this work.

\begin{tabular}{lrl}
\hline Organic dye & $\begin{array}{r}\text { MW } \\
\left(\mathrm{g} \mathrm{mol}^{-1}\right)\end{array}$ & $R_{\mathrm{H}}(\AA)$ \\
\hline Fluorescein & 332 & 5.02, Mustafa et al. (1993) \\
Rhodamine 6G & 443 & 5.89, Müller and Loman (2008) \\
Calcein & 622 & 7.4, Tamba et al. (2010) \\
\hline
\end{tabular}

$(<0.5 \mathrm{wt} \%)$ were required. In Sect. 2.1, the methods used to generate the thin films are discussed, and the rFRAP technique is described in Sect. 2.2.

\subsection{Preparation of thin films containing sucrose, water and trace amounts of fluorescent dye}

The concentrations of sucrose in the thin films studied ranged from 71 to $92.5 \mathrm{wt} \%$ sucrose, which corresponds to $a_{\mathrm{w}}$ values ranging from 0.80 to 0.38 . These films were all supersaturated with respect to crystalline sucrose (i.e. concentrations $>67 \mathrm{wt} \%$ sucrose and $a_{\mathrm{w}}<0.84$ ). To prepare these supersaturated films, the following method was used: first, a solution containing $60 \mathrm{wt} \%$ sucrose in water and trace amounts of dye were prepared gravimetrically. Then, the solution was passed through a $0.02 \mu \mathrm{m}$ filter (Whatman ${ }^{\mathrm{TM}}$; Maidstone, UK) to eliminate impurities (e.g. dust), and a droplet of the prepared solution was placed on a siliconized hydrophobic slide (Hampton Research; Aliso Viejo, CA, USA). Next, the hydrophobic slide containing the droplet was placed inside a flow cell or sealed glass container with a controlled relative humidity (RH). In cases where a flow cell was used, the RH was controlled using a humidified flow of $\mathrm{N}_{2}$ gas (Bodsworth et al., 2010; Koop et al., 2000; Pant et al., 2004). In cases where a sealed glass container was used, the RH was set by placing supersaturated inorganic salt solutions with known water vapour partial pressures (Greenspan, 1977) within the sealed glass containers. The relative humidity was measured with a hygrometer with an uncertainty of $\pm 2.5 \%$. The slide holding the droplet was left inside the flow cell or sealed glass containers for an extended period of time to allow the droplet enough time to come to equilibrium with the surrounding RH. Calculations of the time required for each droplet to come to equilibrium with the surrounding RH (i.e. conditioning time) is discussed in the Supplement (Sect. S1) and reported in Tables S1-S3. Conditioning times used in this work ranged from $30 \mathrm{~min}$ to 93 days. Once equilibrium is reached, the activity of water in the droplet and the gas phase are equal, and $a_{\mathrm{w}}$ can be calculated from RH. The wt $\%$ of sucrose in the droplet was then calculated using the relationship between $a_{\mathrm{w}}$ and wt $\%$ sucrose given by Eq. (2) (Zobrist et al., 2011)

$a_{\mathrm{w}}(T, w)=\frac{1+a w}{1+b w+c w^{2}}+\left(T-T^{\Theta}\right)\left(d w+e w^{2}+f w^{3}+g w^{4}\right)$,

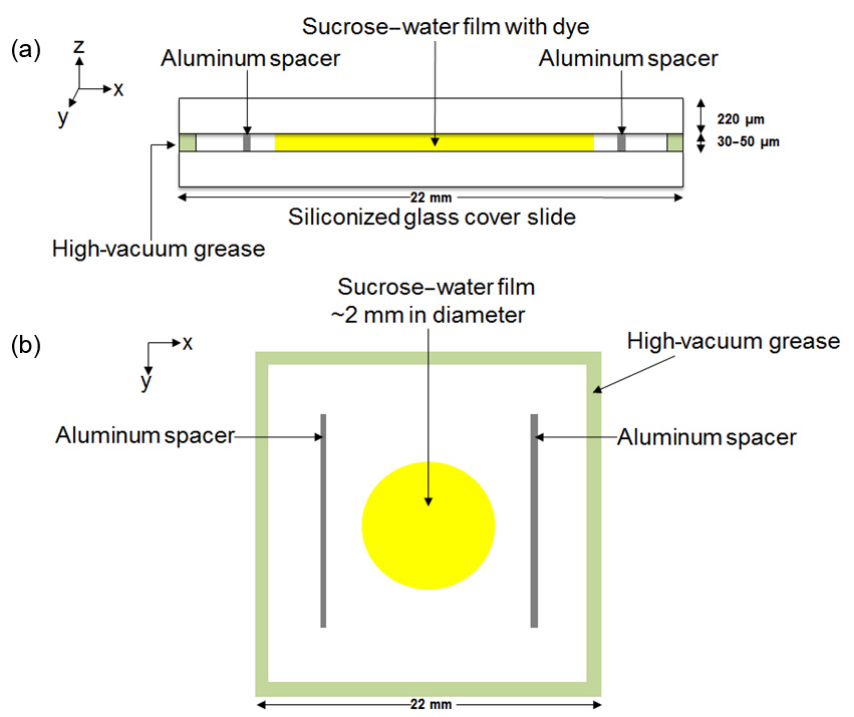

Figure 2. Side view and top view of a thin film containing sucrose, water and a fluorescent dye sandwiched between two hydrophobic glass slides as prepared for use in rFRAP experiments.

where $T$ is the temperature of the experiments $(294.5 \pm 1.0 \mathrm{~K}), \quad T^{\Theta}$ is a reference temperature of $298.15 \mathrm{~K}$ and $w$ is the sucrose weight fraction $(a=-1, b=-0.99721, c=0.13599, d=0.001688, e=$ $-0.005151, f=0.009607$ and $g=-0.006142$ ). After the droplet on the slide was conditioned to a known $\mathrm{RH}$, the droplet was sandwiched between another siliconized hydrophobic slide, producing a film approximately $30-50 \mu \mathrm{m}$ in thickness, determined by an aluminum spacer (Fig. 2). High-vacuum grease around the perimeter of the slides provided a seal. The process of sandwiching the droplet was carried out within a Glove Bag ${ }^{\mathrm{TM}}$ (Glas-Col; Terre Haute, IN, USA), which was inflated with humidified $\mathrm{N}_{2}$ gas. The humidity within the Glove $\mathrm{Bag}^{\mathrm{TM}}$ was set to the same $\mathrm{RH}$ used to condition the droplet to prevent the droplet from being exposed to an uncontrolled RH. Once the thin films were generated and sealed with high-vacuum grease, they were also kept over saturated inorganic salt solutions (in a sealed container) with RH values equal to the RH used to condition the droplets.

Even though the thin films were supersaturated with respect to crystalline sucrose, crystallization was not observed in most cases. This was likely, because the solutions were first passed through a $0.02 \mu \mathrm{m}$ filter to remove any heterogeneous nuclei that could initiate crystallization, and the glass slides used to make the thin films were coated with a hydrophobic material that significantly reduces the ability of these surfaces to promote heterogeneous nucleation (Bodsworth et al., 2010; Pant et al., 2004, 2006; Price et al., 2014; Wheeler and Bertram, 2012). In the few cases where crystallization was observed, the films were not used in the rFRAP experiments. 
The concentrations of the dyes in the thin films were approximately $0.8,0.4$ and $0.3 \mathrm{mM}$ for fluorescein, rhodamine $6 \mathrm{G}$ and calcein, respectively. To prepare thin films containing these dyes, fluorescein disodium salt (Sigma-Aldrich; St. Louis, MO, USA), rhodamine 6G chloride (Acros Organics; Geel, Belgium) and calcein (Sigma-Aldrich) were used. To dissolve calcein in sucrose-water solutions, small amounts $(<0.5 \mathrm{wt} \%)$ of $\mathrm{NaOH}$ were required. Concentrations of the dyes were chosen so that (1) the concentrations were small enough to not significantly influence the viscosity of the sucrose-water solutions, (2) the fluorescence signal was large enough to detect in the rFRAP experiments, and (3) the intensity of the fluorescence signal was linear with concentration of the fluorescent dyes for the range used in the rFRAP experiments. In a separate set of experiments, the intensity of the fluorescence signal as a function of the dye concentration in sucrose-water films was measured (see Supplement, Sect. S2 and Figs. S1-S3). The intensity of the fluorescence signal was found to be linear for the concentrations of dyes used in our experiments.

\section{2 rFRAP technique}

The technique of fluorescence recovery after photobleaching (FRAP) is often utilized in the biological and materials science communities to measure diffusion coefficients in biological materials, single cells and organic polymers (see Braeckmans et al., 2003, 2007; Hatzigrigoriou et al., 2011; Seksek et al., 1997; Smith et al., 1981 and references therein). The rFRAP technique is a recently developed version of FRAP (Deschout et al., 2010). In the rFRAP experiments, a small volume of the thin film was photobleached with a confocal laser scanning microscope, decreasing the fluorescence signal in the photobleached volume. After photobleaching, the fluorescence in this volume was monitored with the same confocal microscope for an extended period of time. Due to the molecular diffusion of organic fluorescent probe molecules, the fluorescence in the photobleached volume recovered, and from the time-dependent recovery of the fluorescence signal, the diffusion coefficient was determined. Additional details are given below.

For the experiments performed using fluorescein and calcein dyes, the rFRAP experiments were performed on a Leica TCS SP5 II confocal laser scanning microscope with a $10 \times$, 0.4 numerical aperture (NA) objective and a pinhole setting of $53 \mu \mathrm{m}$. Photobleaching was performed using a $488 \mathrm{~nm} \mathrm{Ar}$ laser set at $1.18 \mathrm{~mW}$, and after photobleaching images were acquired with the same laser line at $2.2 \mu \mathrm{W}$. Experiments were performed using Leica FRAP wizard software using the "zoom-in" bleach mode.

For the experiments performed using rhodamine $6 \mathrm{G}$, the rFRAP experiments were performed on a Zeiss Axio Observer LSM $510 \mathrm{MP}$ laser scanning microscope with a $10 \times$, 0.3 NA objective and a pinhole setting of $80 \mu \mathrm{m}$. Photobleaching was performed using a $543 \mathrm{~nm}$ helium-neon
$(\mathrm{HeNe})$ laser set at $330 \mu \mathrm{W}$. After photobleaching, images were acquired with the same laser line at $4.08 \mu \mathrm{W}$ laser intensity. Experiments were performed using the Zen 2008 software with the "zoom-in" bleach mode. In all experiments, the exposure time used for photobleaching was chosen such that it resulted in approximately $30 \%$ of the fluorescent molecules being photobleached in the region of interest (ROI) as suggested by Deschout et al. (2010). Deschout et al. (2010) previously showed that diffusion coefficients measured with rFRAP were independent of the extent of photobleaching up to a depletion of $50 \%$ of the fluorescent signal in the ROI.

The geometry of the photobleached region was rectangular, with a length $l_{x}$ and a width $l_{y}$. Bleached areas ranged from $5 \times 5$ to $36 \times 36 \mu \mathrm{m}^{2}$, depending on the diffusion rates. Smaller photobleached regions were used in cases with slow diffusion rates to shorten the fluorescence recovery time. The specific bleach sizes used in the experiments are indicated in Tables S1-S3. In a separate set of experiments, we measured the diffusion coefficient of calcein in a $72 \mathrm{wt} \%$ sucrose thin film as a function of the bleach area. The results show that the diffusion coefficients varied by less than the uncertainty in the measurements when the bleach size was varied from $1 \times 1$ to $50 \times 50 \mu \mathrm{m}^{2}$ (Fig. S4); this is consistent with previous rFRAP studies (Deschout et al., 2010).

Although there could be local heating during the photobleaching step, this is not expected to affect the measured diffusion coefficient, since the thermal diffusivity in the samples is orders of magnitude faster than the molecular diffusivity. For example, the thermal diffusivity of water is $\sim 1 \times 10^{-3} \mathrm{~cm}^{2} \mathrm{~s}^{-1}$ at room temperature, while the molecular diffusion in our experiments is $1 \times 10^{-8} \mathrm{~cm}^{2} \mathrm{~s}^{-1}$. As a result, any local heating during photobleaching will be dissipated to the surrounding environment on a time scale much shorter than the measurements of molecular diffusion. Measurements of diffusion coefficients as a function of the bleach area (Fig. S4) support this conclusion. In these experiments, the energy absorbed by the bleached region was varied by 3 orders of magnitude. Nevertheless, the measured diffusion coefficient was found to be independent of the amount of energy absorbed by the bleached region.

\subsection{Extraction of diffusion coefficients from rFRAP data}

Shown in Fig. 3 are examples of images recorded during an rFRAP experiment. Figure 3 a shows an image of the film prior to photobleaching, and Fig. 3b-f shows images after photobleaching. All the images after photobleaching are normalized using an image recorded prior to photobleaching or using an area in each image not influenced by photobleaching. To reduce noise, all images were converted from a resolution of $512 \times 512$ pixels to $128 \times 128$ pixels by averaging.

The images recorded during the rFRAP experiments (shown in Fig. 3) represent fluorescence intensities as a func- 

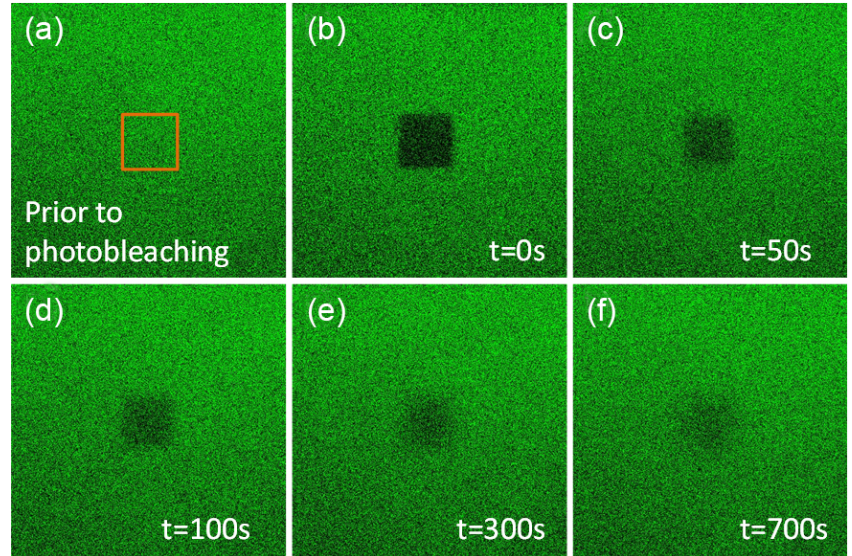

Figure 3. Images recorded during an rFRAP experiment using a thin film composed of $76 \mathrm{wt} \%$ sucrose solution $\left(a_{\mathrm{w}}=0.75\right)$ and trace amounts of rhodamine $6 \mathrm{G}(0.4 \mathrm{mM})$. The image in (a) was recorded before photobleaching, the image in (b) was recorded immediately after photobleaching a $36 \times 36 \mu \mathrm{m}^{2}$ area and the images in panels (c-f) were recorded at 50, 100, 300 and 700 s after photobleaching, respectively. The orange square in (a) represents the $36 \times 36 \mu \mathrm{m}^{2}$ area selected for photobleaching.

tion of position $x$ and $y$ for different times $t$ after photobleaching. The mathematical description for fluorescence intensity as a function of $x, y$ and $t$ (after photobleaching a rectangular profile with a laser scanning confocal microscope) is given by the following equation (Deschout et al., 2010):

$$
\begin{aligned}
\frac{F(x, y, t)}{F_{0}(x, y)} & =1-\frac{K_{0}}{4}\left(\operatorname{erf}\left(\frac{x+\frac{l_{x}}{2}}{\sqrt{w(t)}}\right)-\operatorname{erf}\left(\frac{x-\frac{l_{x}}{2}}{\sqrt{w(t)}}\right)\right) \\
& \times\left(\operatorname{erf}\left(\frac{y+\frac{l_{y}}{2}}{\sqrt{w(t)}}\right)-\operatorname{erf}\left(\frac{y-\frac{l_{y}}{2}}{\sqrt{w(t)}}\right)\right) .
\end{aligned}
$$

$F(x, y, t)$ represents the fluorescence intensity at positions $x$ and $y$ at time $t$ after photobleaching, $F_{0}(x, y)$ is the fluorescence intensity at positions $x$ and $y$ prior to photobleaching, $K_{0}$ is related to the fraction of molecules photobleached in the rectangle and $l_{x}$ and $l_{y}$ are the lengths of the photobleached rectangle in the $x$ and $y$ directions, respectively. The parameter $w$ is described by

$w(t)=r^{2}+4 D t$,

where $r$ is the resolution parameter of the microscope and $D$ is the diffusion coefficient of the dye. Although Eq. (3) was derived with the assumption that the degree of photobleaching is independent of the $z$ direction (i.e. the depth in the thin film), Deschout et al. (2010) have shown that Eq. (3) can be used to extract accurate diffusion coefficients when using a $10 \times$ objective lens with a low numerical aperture (0.45) together with thin films ( $120 \mu \mathrm{m}$ thick); this combination provides a nearly cylindrical photobleached geometry. In our work, we used lower numerical apertures (0.3-0.4) and thinner films $(30-50 \mu \mathrm{m})$ than Deschout et al.

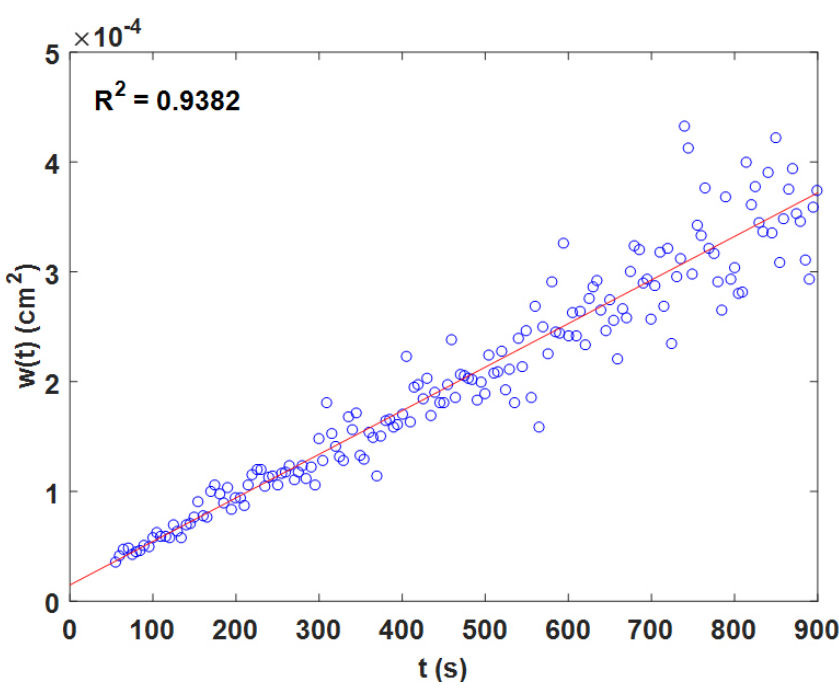

Figure 4. Plot of $w$ versus time for rhodamine $6 \mathrm{G}$ in a $76 \mathrm{wt} \%$ sucrose solution ( $a_{\mathrm{w}}=0.75$ ). The red line is a linear fit to the data. The diffusion coefficient was determined from the slope of the line.

Through a fitting procedure, Eq. (3) was used to extract values of $w(t)$ from the fluorescence images recorded after photobleaching. In the fitting procedure, $K_{0}, w(t)$ and the location of the center of the photobleached region were left as free parameters as was an additional normalization factor, which usually returned a value close to 1 because the images were normalized prior to fitting. After the values of $w(t)$ were determined from each of the fluorescence images, $w(t)$ was plotted versus $t$ such as in Fig. 4. A straight line was then fit to this data, and the diffusion coefficient was determined from slope of the line and Eq. (4). For each concentration of sucrose and for each organic dye, the diffusion coefficient was determined at least nine times (three different thin films were used and at least three measurements were carried out on each thin film).

In addition to molecular diffusion, recovery of the signal in the photobleached region can potentially occur through reversible photobleaching (i.e. photoswitching). To determine whether this mechanism is important, we have carried out the following additional experiments. We prepared droplets with sizes between 10 and $50 \mu \mathrm{m}$ in diameter containing sucrose, water and trace amounts of dye (conditioned at $60 \%$ $\mathrm{RH}$ ), and we photobleached the dye uniformly throughout the droplet until the fluorescence intensity was decreased by $30 \%$. Next, we monitored the integrated fluorescence intensity of the entire droplet as a function of time after photobleaching. Since the photobleaching was performed uniformly on the entire droplet, the dye concentration was uniform throughout the droplet after photobleaching, which eliminated the possibility of diffusion due to concentration gradients. Furthermore, since we monitored the integrated fluorescence intensity of the entire droplet, diffusion due to concentration gradients would not be detected. In these ex- 
periments we did see a small recovery (for fluorescein, 15$40 \%$; for rhodamine, $15-40 \%$; and for calcein, $10-20 \%$ of the photobleached signal) over a short time scale (recovery time was 15,50 and $20 \mathrm{~s}$ for fluorescein, rhodamine $6 \mathrm{G}$ and calcein, respectively). We attributed this fast recovery to reversible photobleaching, which has been previously observed (Mueller et al., 2012; Sinnecker et al., 2005). To take this reversible photobleaching into account when calculating diffusion coefficients, we only used data recorded 15, 50 and $20 \mathrm{~s}$ after photobleaching for fluorescein, rhodamine $6 \mathrm{G}$ and calcein, respectively.

\section{Results and discussion}

\subsection{Diffusion coefficients of the three fluorescent organic dyes in sucrose-water solutions}

Shown in Fig. 5 are the diffusion coefficients for fluorescein in sucrose-water solutions. Several different $x$ axes (wt $\%$ sucrose, $a_{\mathrm{w}}, T_{\mathrm{g}} / T$ and viscosity) are included to put the results in context. $T_{\mathrm{g}}$ and $T$ are the glass transition temperature and the temperature of the matrix, respectively. $T_{\mathrm{g}}$ was calculated from wt $\%$ sucrose using the relationship between $T_{\mathrm{g}}$ and wt \% sucrose given in Champion et al. (1997). Viscosity was calculated from $a_{\mathrm{w}}$ using viscosity data (Migliori et al., 2007; Power et al., 2013; Quintas et al., 2006; Telis et al., 2007) parameterized as a function $a_{\mathrm{w}}$.

Figure 5 illustrates that the diffusion coefficient of fluorescein in sucrose-water solutions is strongly dependent on $a_{\mathrm{w}}$, with the diffusion coefficient varying by approximately 5 orders of magnitude as $a_{\mathrm{w}}$ varied from 0.38 to 0.80 . This strong dependence of the diffusion coefficient on $a_{\mathrm{w}}$ is because water acts as a plasticizer in sucrose-water mixtures; as the water content in the matrix increases, the viscosity of the matrix decreases (Power et al., 2013). At the lowest $a_{\mathrm{w}}$ studied, the average diffusion coefficient of fluorescein was $1.9 \times 10^{-13} \mathrm{~cm}^{2} \mathrm{~s}^{-1}$.

To test the Stokes-Einstein relation, in Fig. 5 the measured diffusion coefficients for fluorescein are compared with diffusion coefficients calculated with the Stokes-Einstein relation and previous viscosity measurements of sucrose-water solutions (Migliori et al., 2007; Power et al., 2013; Quintas et al., 2006; Telis et al., 2007). To calculate the diffusion coefficients, a hydrodynamic radius of $5.02 \AA$ was used for fluorescein based on measurements of fluorescein diffusion coefficients in water (Mustafa et al., 1993). At $a_{\mathrm{w}} \geq 0.6$ (which corresponds to $T_{\mathrm{g}} / T \leq 0.81$ and a viscosity of $\leq 360 \mathrm{~Pa} \mathrm{~s}$ ), the measured diffusion coefficients are consistent with the predicted diffusion coefficients. At a water activity of 0.38 (which corresponds to a $T_{\mathrm{g}} / T$ value of 0.94 and a viscosity of approximately $3.3 \times 10^{6} \mathrm{~Pa}$ s), the Stokes-Einstein equation underpredicts the diffusion coefficient by a factor of approximately 118 (minimum factor of 10 and maximum factor of

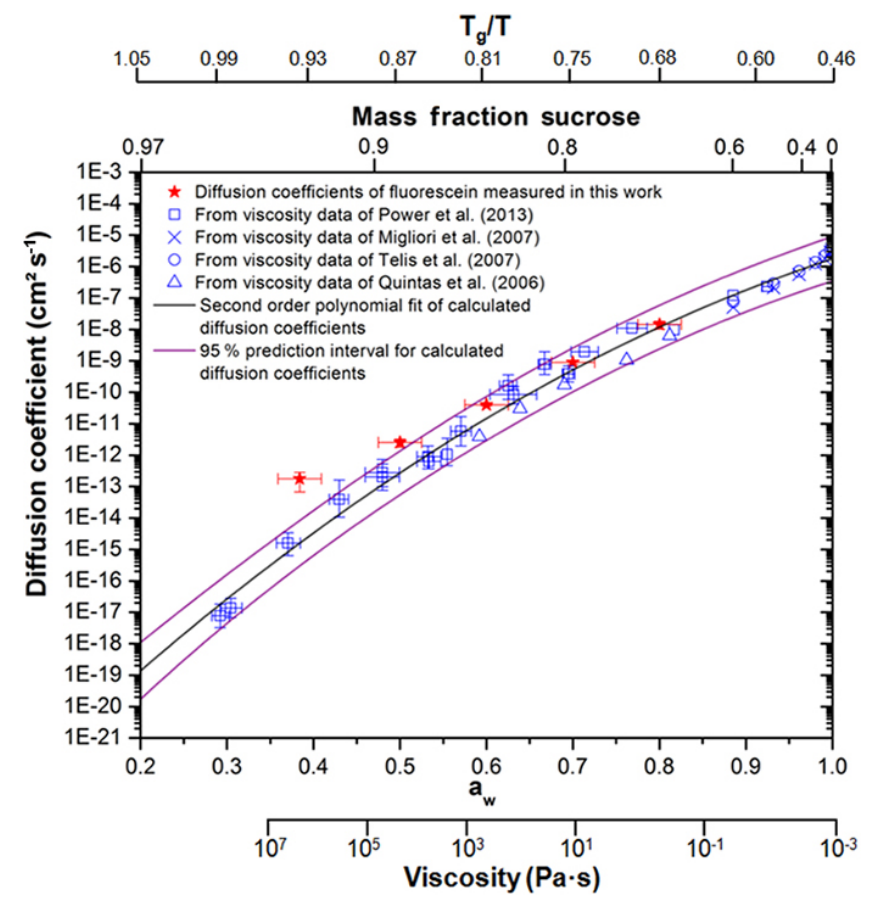

Figure 5. A comparison of measured diffusion coefficients of fluorescein in sucrose-water films from this work (red stars) with predicted diffusion coefficients based on measured viscosities of sucrose-water solutions and the Stokes-Einstein equation from Power et al. (2013) (blue squares), Migliori et al. (2007) (blue crosses), Telis et al. (2007) (blue circles) and Quintas et al. (2006) (blue triangles). The $x$ error bars for this work correspond to the uncertainty in the determination of $a_{\mathrm{w}}$ from the hygrometer. The $y$ errors for this work correspond to $95 \%$ confidence intervals from measurement repeats. Several different $x$ axes (wt $\%$ sucrose, $a_{\mathrm{w}}$, $T_{\mathrm{g}} / T$ and viscosity) are included to help put the results in context. $T$ represents the temperature of the experiment $(294.5 \mathrm{~K})$, and $T_{\mathrm{g}}$ represents the glass transition temperature of sucrose-water solutions.

977 if the uncertainties in the measured diffusion coefficients and the predicted diffusion coefficients are considered).

The difference between the measured diffusion coefficient and the Stokes-Einstein predicted diffusion coefficient at a water activity of 0.38 may be partly due to a decreasing hydrodynamic radius of fluorescein with decreasing water activity (Champion et al., 1997). However, the hydrodynamic radius is not expected to vary by an order of magnitude when the water activity is varied from 0.6 to 0.38 . Hence, a change in the hydrodynamic radius is not expected to explain the entire difference at a water activity of 0.38 .

Shown in Figs. 6 and 7 are the diffusion coefficients of rhodamine $6 \mathrm{G}$ and calcein in sucrose-water solutions. The diffusion coefficients of these two dyes also depended strongly on $a_{\mathrm{w}}$. For rhodamine 6G, the diffusion coefficient appears to vary by more than 5 orders of magnitude as $a_{\mathrm{w}}$ varies from 0.38 to 0.80 . For calcein, the diffusion coefficient varied approximately 4 orders of magnitude as $a_{\mathrm{w}}$ was varied 


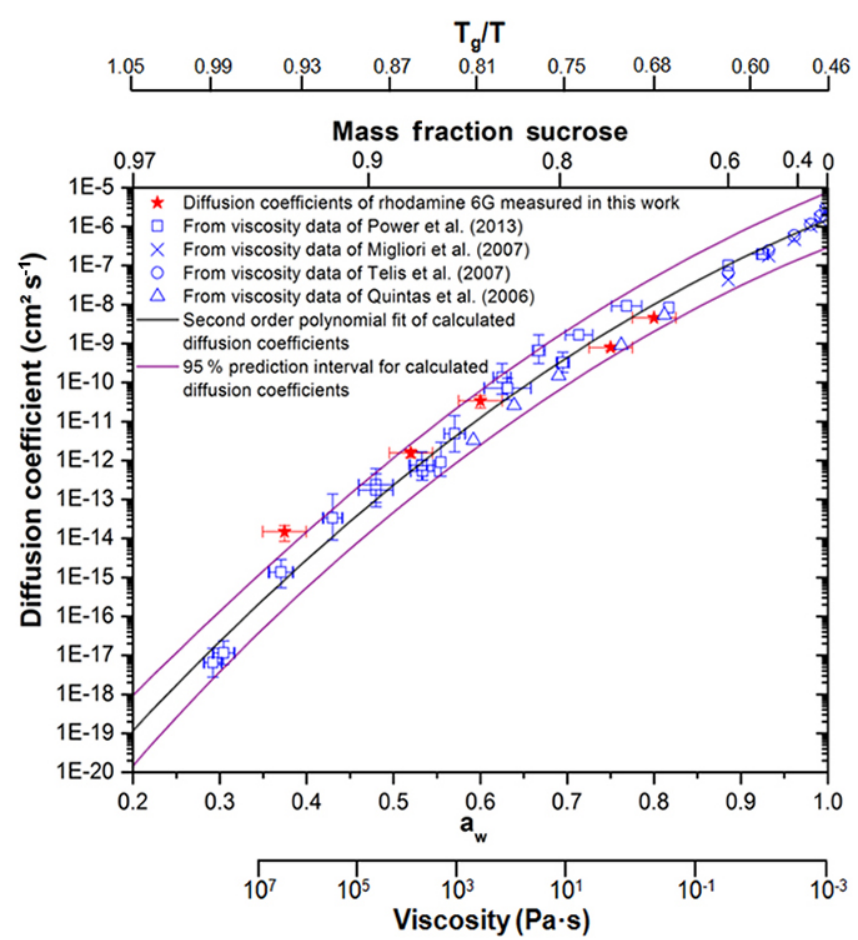

Figure 6. A comparison of measured diffusion coefficients of rhodamine $6 \mathrm{G}$ in sucrose-water films from this work (red stars) with predicted diffusion coefficients based on measured viscosities of sucrose-water solutions and the Stokes-Einstein equation from Power et al. (2013) (blue squares), Migliori et al. (2007) (blue crosses), Telis et al. (2007) (blue circles) and Quintas et al. (2006) (blue triangles). The $x$ error bars for this work correspond to the uncertainty in the determination of $a_{\mathrm{w}}$ from the hygrometer. The $y$ errors for this work correspond to $95 \%$ confidence intervals from measurement repeats. Several different $x$ axes (wt $\%$ sucrose, $a_{\mathrm{W}}$, $T_{\mathrm{g}} / T$ and viscosity) are included to help put the results in context. $T$ represents the temperature of the experiment $(294.5 \mathrm{~K})$, and $T_{\mathrm{g}}$ represents the glass transition temperature of sucrose-water solutions.

from 0.38 to 0.80 . At the lowest $a_{\mathrm{w}}$ studied (0.38), the average diffusion coefficients for rhodamine $6 \mathrm{G}$ and calcein were $1.5 \times 10^{-14}$ and $7.7 \times 10^{-14} \mathrm{~cm}^{2} \mathrm{~s}^{-1}$, respectively.

Also included in Figs. 6 and 7 are the diffusion coefficients calculated using the Stokes-Einstein relation and the viscosities of sucrose-water solutions reported in the literature (Migliori et al., 2007; Power et al., 2013; Quintas et al., 2006; Telis et al., 2007). When calculating diffusion coefficients using the Stokes-Einstein equation, hydrodynamic radii of 5.89 and $7.4 \AA$ were used for rhodamine $6 \mathrm{G}$ and calcein, respectively, based on the measured diffusion coefficients of these dyes in water (Müller and Loman, 2008; Tamba et al., 2010). Figures 6 and 7 show that, similar to fluorescein, the measured diffusion coefficients are consistent with the predicted diffusion coefficients at $a_{\mathrm{w}} \geq 0.6$ (which corresponds to $T_{\mathrm{g}} / T \leq 0.81$ and a viscosity of $\leq 360 \mathrm{Pas}$ ). On the other hand, at a water activity of 0.38 (which corre-

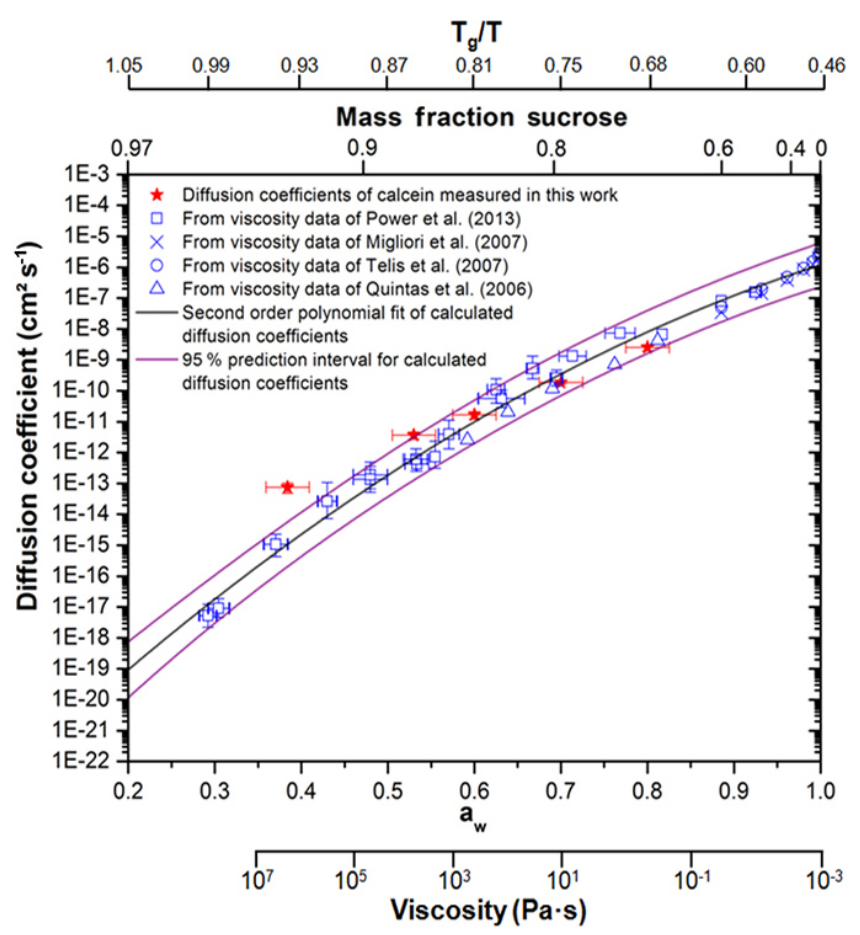

Figure 7. Comparison of measured diffusion coefficients of calcein in sucrose-water films from this work (red stars) with predicted diffusion coefficients based on measured viscosities of sucrosewater solutions and the Stokes-Einstein equation from Power et al. (2013) (blue squares), Migliori et al. (2007) (blue crosses), Telis et al. (2007) (blue circles) and Quintas et al. (2006) (blue triangles). The $x$ error bars for this work correspond to the uncertainty in the determination of $a_{\mathrm{w}}$ from the hygrometer. The $y$ errors for this work correspond to $95 \%$ confidence intervals from measurement repeats. Several different $x$ axes (wt $\%$ sucrose, $a_{\mathrm{w}}, T_{\mathrm{g}} / T$ and viscosity) are included to help put the results in context. $T$ represents the temperature of the experiment $(294.5 \mathrm{~K})$, and $T_{\mathrm{g}}$ represents the glass transition temperature of sucrose-water solutions.

sponds to a $T_{\mathrm{g}} / T$ value of 0.94 and a viscosity of approximately $3.3 \times 10^{6} \mathrm{~Pa} \mathrm{~s}$ ), the Stokes-Einstein equation appears to underpredict the diffusion coefficients. For rhodamine $6 \mathrm{G}$, the measured diffusion coefficient is greater than the predicted diffusion coefficient by a factor of approximately 17 (minimum factor of 3 and maximum factor of 104 if the uncertainties in the measured diffusion coefficients and the predicted diffusion coefficients are considered). For calcein, the measured diffusion coefficient is greater than the predicted diffusion coefficient by approximately 70 (minimum factor of 8 and maximum factor of 494 if the uncertainties in the measured diffusion coefficients and the predicted diffusion coefficients are considered).

The hydrodynamic radii of fluorescein, rhodamine $6 \mathrm{G}$ and calcein are 5.02, 5.89 and $7.4 \AA$, respectively (Table 1). The radius of sucrose is roughly $4.5 \AA$ based on the density of amorphous sucrose. Assuming that the breakdown of the Stokes-Einstein equation depends only on the ratio of the 
radius of the fluorescent probe to the radius of the matrix molecules, we would expect the best agreement for calcein. Unfortunately, the uncertainties in our experiments are too large to test this relationship.

\subsection{Comparison with previous measurements of organics or organometallics in sucrose-water matrices}

In Table 2, we summarize previous studies that tested the Stokes-Einstein relation using organics or organometallics in sucrose-water mixtures. Champion et al. (1997) measured the diffusion coefficients of fluorescein in sucrose-water solutions at temperatures ranging from 20 to $-15^{\circ} \mathrm{C}$, and Corti et al. (2008) measured the diffusion coefficients of fluorescein in sucrose-water solutions at approximately $20^{\circ} \mathrm{C}$. The results from Champion et al. (1997) indicate that the Stokes-Einstein relation underpredicted the diffusion coefficients for $T_{\mathrm{g}} / T \gtrsim 0.9$, while good agreement is observed at smaller $T_{\mathrm{g}} / T$ values. The results from Corti et al. (2008) show disagreement between the measured and predicted diffusion coefficients for $T_{\mathrm{g}} / T \gtrsim 0.7$ and good agreement at smaller $T_{\mathrm{g}} / T$ values. Longinotti and Corti (2007) measured the diffusion of ferrocene methanol in sucrose-water solutions. Their results indicate that the Stokes-Einstein relation underpredicts diffusion coefficients for $T_{\mathrm{g}} / T \gtrsim 0.8$, while good agreement is observed at smaller $T_{\mathrm{g}} / T$ values. More recently, Price et al. (2016) measured the diffusion coefficients of sucrose in sucrose-water solutions at $296 \mathrm{~K}$ (Price et al., 2016). Their results suggest disagreement for $T_{\mathrm{g}} / T \gtrsim 0.88$ based on an analysis similar to the one discussed in Sect. 3.1.

In our studies with fluorescein, rhodamine $6 \mathrm{G}$ and calcein, the breakdown of the Stokes-Einstein relation is observed at a $T_{\mathrm{g}} / T$ value of approximately 0.93 ; no indication of breakdown is apparent at a $T_{\mathrm{g}} / T$ value of approximately 0.81 . At a $T_{\mathrm{g}} / T$ value of 0.87 , there is some indication of breakdown in our studies since the measured average diffusion coefficient for fluorescein and rhodamine 6G is outside the $95 \%$ prediction intervals. These observations are consistent with the results from Champion et al. (1997) and Price et al., and the $T_{\mathrm{g}} / T$ values at which we observed breakdown is only slightly higher than the values based on Corti et al. (2008) and Longinotti and Corti (2007).

\subsection{Comparison with the diffusion of water in sucrose-water solutions}

Compared to the fluorescent organic dyes studied here, larger disagreement has been observed between measured and predicted diffusion coefficients for water in sucrose-water mixtures (Power et al., 2013; Price et al., 2014). To illustrate this point, in Fig. 8 the diffusion coefficients of water in sucrose-water solutions measured by Price et al. (2014) are shown and compared with the predicted diffusion coefficients for water in sucrose-water solutions based on the

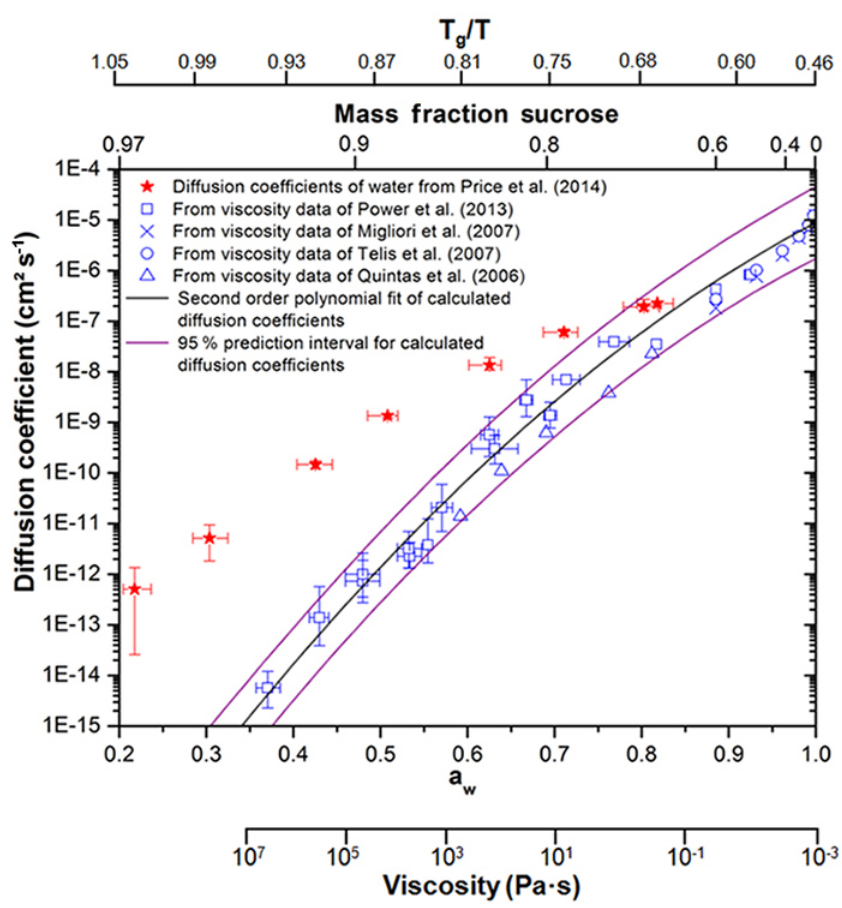

Figure 8. A comparison of measured diffusion coefficients of water in sucrose-water films from Price et al. (2014) (red stars) with predicted diffusion coefficients based on measured viscosities of sucrose-water solutions and the Stokes-Einstein equation from Power et al. (2013) (blue squares) Migliori et al. (2007) (blue crosses), Telis et al. (2007) (blue circles) and Quintas et al. (2006) (blue triangles). Several different $x$ axes (wt $\%$ sucrose, $a_{\mathrm{w}}, T_{\mathrm{g}} / T$ and viscosity) are included to help put the results in context. T represents the temperature of the experiment $(294.5 \mathrm{~K})$, and $T_{\mathrm{g}}$ represents the glass transition temperature of sucrose-water solutions.

Stokes-Einstein relation and viscosity measurements. The measurements by Price et al. (2014) are in good agreement with other measurements at $a_{\mathrm{w}} \geq 0.3$ (Davies and Wilson, 2016; Price et al., 2014; Rampp et al., 2000; Zobrist et al., 2011). To predict the diffusion coefficients of water in Fig. 8, a hydrodynamic radius of $1.41 \AA$ was used (Pang, 2014). Figure 8 shows that even at a water activity of 0.6 , the Stokes-Einstein relation underpredicts the diffusion coefficient by approximately 10 to 1000 . At a water activity of 0.38 , the Stokes-Einstein underpredicts the diffusion coefficient of water by approximately $10^{3}$ to $10^{5}$. For the case of small molecules like water, other relations besides the Stokes-Einstein relation may be needed (Essam, 1980; Marshall et al., 2016; Molinero et al., 2003; Murata et al., 1999). In Fig. 9, the measured diffusion coefficients of fluorescein, rhodamine $6 \mathrm{G}$ and calcein are compared with the diffusion coefficients of water measured by Price et al. (2014). In all cases, the diffusion coefficients are a strong function of water activity, and the diffusion coefficients of water are much larger than the diffusion coefficients of the organic fluorescent dyes. 
Table 2. Summary of results from previous studies that tested the breakdown of the Stokes-Einstein relation using organics or organometallics in sucrose-water mixtures.

\begin{tabular}{llrl}
\hline Matrix & $\begin{array}{l}\text { Diffusing } \\
\text { molecule }\end{array}$ & $\begin{array}{r}T_{\mathrm{g}} / T \text { where } \\
\text { breakdown is } \\
\text { clearly discernable }\end{array}$ & Reference \\
\hline Sucrose-water & fluorescein & 0.9 & Champion et al. (1997) \\
Sucrose-water & fluorescein & $0.68-0.78$ & Corti et al. (2008a) \\
Sucrose-water & ferrocene methanol & 0.8 & Longinotti and Corti (2007) \\
Sucrose-water & sucrose & 0.88 & Price et al. (2016) \\
\hline
\end{tabular}

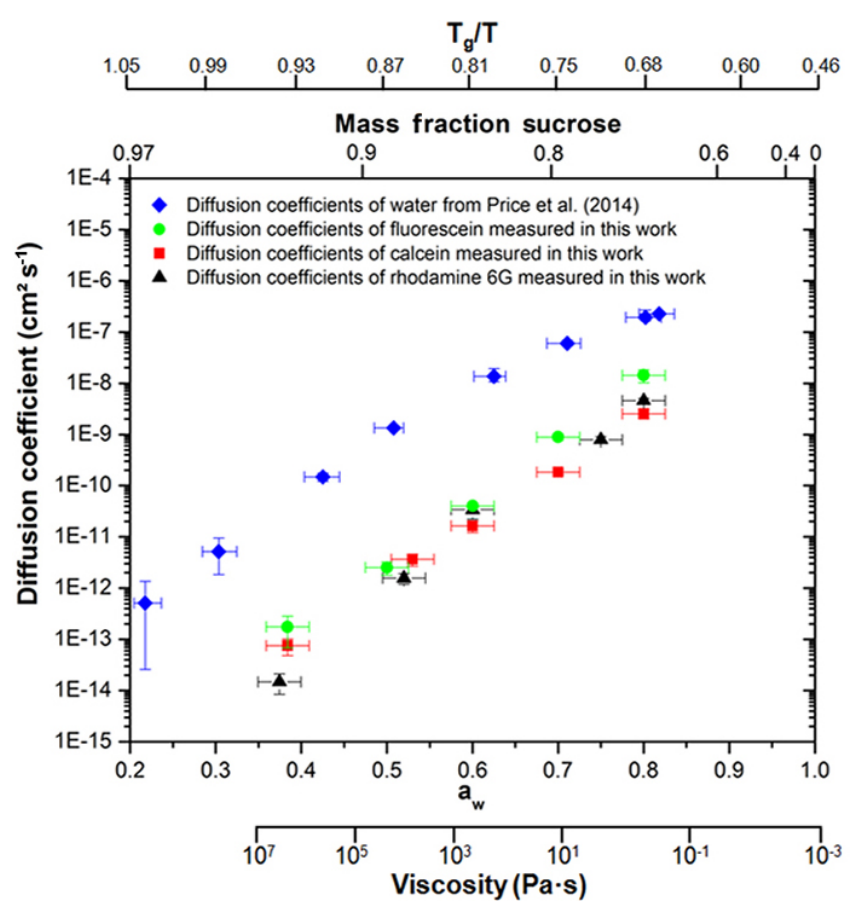

Figure 9. A comparison of the measured diffusion coefficients of fluorescein (green circles), rhodamine 6G (black triangles) and calcein (red squares) with the measured diffusion coefficients of water by Price et al. (2014) (blue diamonds).

\section{Summary and conclusions}

Using rFRAP, we measured the diffusion coefficients of three fluorescent organic dyes (fluorescein, rhodamine $6 \mathrm{G}$ and calcein) in sucrose-water solutions for water activities $\geq 0.38$ (which correspond to viscosities $\leq 3.3 \times 10^{6} \mathrm{~Pa}$ and $T_{\mathrm{g}} / T \leq 0.94$ ). The diffusion coefficients of the organic dyes depended strongly on the water activity, with the diffusion coefficients varying by approximately $4-5$ orders of magnitude as $a_{\mathrm{w}}$ varied from 0.38 to 0.80 .

The measured diffusion coefficients were compared to diffusion coefficients calculated using the Stokes-Einstein relation and viscosities from the literature. For all three dyes studied, the Stokes-Einstein relation predicts diffusion coefficients in agreement with the measured diffusion coefficients when $a_{\mathrm{w}} \geq 0.6$ or when the solution viscosity is $\leq 360 \mathrm{~Pa}$ s and $T_{\mathrm{g}} / T \leq 0.81$. In contrast, at $a_{\mathrm{w}}=0.38$ or when the solution viscosity equals $3.3 \times 10^{6} \mathrm{Pas}$ and $T_{\mathrm{g}} / T=0.94$, the Stokes-Einstein relation underpredicted the diffusion coefficients of fluorescein, rhodamine $6 \mathrm{G}$ and calcein by a factor of 118 (minimum of 10 and maximum of 977), a factor of 17 (minimum of 3 and maximum of 104) and a factor of 70 (minimum of 8 and maximum of 494), respectively.

The range of $T_{\mathrm{g}} / T$ values over which we observed the breakdown of the Stokes-Einstein relation is broadly consistent with previous measurements that tested the breakdown of the Stokes-Einstein relation using organics or organometallics in sucrose-water mixtures. Compared to the fluorescent organic dyes studied here, larger disagreement has been observed between the measured and predicted diffusion coefficients of water in sucrose-water mixtures (Power et al., 2013; Price et al., 2014). At a water activity of 0.38 , the Stokes-Einstein underpredicts the diffusion coefficient of water by a factor of approximately $10^{3}$ to $10^{5}$. The results presented here should be useful in developing corrections for the Stokes-Einstein equation and making estimations of the diffusion rates of organic molecules in secondary organic aerosol particles found in the atmosphere.

\section{Data availability}

The underlying material and related items for this manuscript are located in the Supplement.

\section{The Supplement related to this article is available online at doi:10.5194/acp-17-2423-2017-supplement.}

Competing interests. The authors declare that they have no conflict of interest. 
Acknowledgements. This work was carried out in the Laboratory for Advanced Spectroscopy and Imaging Research (LASIR) at the University of British Columbia in Vancouver and supported by funding from the Natural Sciences and Engineering Research Council of Canada and the Canadian Foundation for Innovation.

Edited by: D. Topping

Reviewed by: two anonymous referees

\section{References}

Abramson, E., Imre, D., Beránek, J., Wilson, J., and Zelenyuk, A.: Experimental determination of chemical diffusion within secondary organic aerosol particles, Phys. Chem. Chem. Phys., 15, 2983-2991, doi:10.1039/c2cp44013j, 2013.

Adler, G., Koop, T., Haspel, C., Taraniuk, I., Moise, T., Koren, I., Heiblum, R. H., and Rudich, Y.: Formation of highly porous aerosol particles by atmospheric freeze-drying in ice clouds, P. Natl. Acad. Sci. USA, 110, 20414-20419, doi:10.1073/pnas.1317209110, 2013.

Aiken, A. C., Decarlo, P. F., Kroll, J. H., Worsnop, D. R., Huffman, J. A., Docherty, K. S., Ulbrich, I. M., Mohr, C., Kimmel, J. R., Sueper, D., Sun, Y., Zhang, Q., Trimborn, A., Northway, M., Ziemann, P. J., Canagaratna, M. R., Onasch, T. B., Alfarra, M. R., Prevot, A. S. H., Dommen, J., Duplissy, J., Metzger, A., Baltensperger, U., and Jimenez, J. L.: O / C and OM / OC ratios of primary, secondary, and ambient organic aerosols with highresolution time-of-flight aerosol mass spectrometry, Environ. Sci. Technol., 42, 4478-4485, doi:10.1021/es703009q, 2008.

Bateman, A. P., Gong, Z., Liu, P., Sato, B., Cirino, G., Zhang, Y., Artaxo, P., Bertram, A. K., Manzi, A. O., Rizzo, L. V, Souza, R. A. F., Zaveri, R. A., and Martin, S. T.: Sub-micrometre particulate matter is primarily in liquid form over Amazon rainforest, Nat. Geosci., 9, 34-37, doi:10.1038/ngeo2599, 2016.

Berkemeier, T., Shiraiwa, M., Poschl, U., and Koop, T.: Competition between water uptake and ice nucleation by glassy organic aerosol particles, Atmos. Chem. Phys., 14, 12513-12531, doi:10.5194/acp-14-12513-2014, 2014.

Blackburn, F. R., Cicerone, M. T., Hietpas, G., Wagner, P. A., and Ediger, M. D.: Cooperative motion in fragile liquids near the glass-transition: Probe reorientation in oterphenyl and polystyrene, J. Non.-Cryst. Sol., 172, 256-264, doi:10.1016/0022-3093(94)90444-8, 1994.

Blackburn, F. R., Wang, C. Y., and Ediger, M. D.: Translational and rotational motion of probes in supercooled 1,3,5tris(naphthyl)benzene, J. Phys. Chem., 100, 18249-18257, doi:10.1021/jp9622041, 1996.

Bodsworth, A., Zobrist, B., and Bertram, A. K.: Inhibition of efflorescence in mixed organic-inorganic particles at temperatures less than 250 K, Phys. Chem. Chem. Phys., 12, 12259-12266, doi:10.1039/c0cp00572j, 2010.

Bones, D. L., Reid, J. P., Lienhard, D. M., and Krieger, U. K.: Comparing the mechanism of water condensation and evaporation in glassy aerosol, P. Natl. Acad. Sci. USA, 109, 11613-11618, doi:10.1073/pnas.1200691109, 2012.

Booth, A. M., Murphy, B., Riipinen, I., Percival, C. J., and Topping, D. O.: Connecting bulk viscosity measurements to kinetic limitations on attaining equilibrium for a model aerosol composition,
Environ. Sci. Technol., 48, 9298-9305, doi:10.1021/es501705c, 2014.

Braeckmans, K., Peeters, L., Sanders, N. N., De Smedt, S. C., and Demeester, J.: Three-dimensional fluorescence recovery after photobleaching with the confocal scanning laser microscope, Biophys. J., 85, 2240-2252, doi:10.1016/S0006-3495(03)746499, 2003.

Braeckmans, K., Remaut, K., Vandenbroucke, R. E., Lucas, B., De Smedt, S. C., and Demeester, J.: Line FRAP with the confocal laser scanning microscope for diffusion measurements in small regions of 3-D samples, Biophys. J., 92, 2172-2183, doi:10.1529/biophysj.106.099838, 2007.

Champion, D., Hervet, H., Blond, G., LeMeste, M., and Simatos, D.: Translational diffusion in sucrose solutions in the vicinity of their glass transition temperature, J. Phys. Chem. B., 101, 1067410679, doi:10.1021/jp971899i, 1997.

Chang, I., Fujara, F., Geil, B., Heuberger, G., Mangel, T., and Sillescu, H.: Translational and rotational molecular motion in supercooled liquids studied by NMR and forced Rayleigh scattering, J. Non.-Cryst. Solids, 172, 248-255, doi:10.1016/00223093(94)90443-X, 1994.

Chen, Q., Farmer, D. K., Schneider, J., Zorn, S. R., Heald, C. L., Karl, T. G., Guenther, A., Allan, J. D., Robinson, N., Coe, H., Kimmel, J. R., Pauliquevis, T., Borrmann, S., Pöschl, U., Andreae, M. O., Artaxo, P., Jimenez, J. L., and Martin, S. T.: Mass spectral characterization of submicron biogenic organic particles in the Amazon Basin, Geophys. Res. Lett., 36, L20806, doi:10.1029/2009GL039880, 2009.

Cicerone, M. T., Blackburn, F. R., and Ediger, M. D.: How do molecules move near $\mathrm{Tg}$ ? Molecular rotation of six probes in o-terphenyl across 14 decades in time, J. Chem. Phys., 102, 471479, doi:10.1063/1.469425, 1995.

Corti, H. R., Frank, G. A., and Marconi, M. C.: An alternate solution of fluorescence recovery kinetics after spot-bleaching for measuring diffusion coefficients, 2. Diffusion of fluorescein in aqueous sucrose solutions, J. Solution Chem., 37, 1593-1608, doi:10.1007/s10953-008-9329-4, 2008a.

Corti, H. R., Frank, G. A., and Marconi, M. C.: Diffusion-viscosity decoupling in supercooled aqueous trehalose solutions, J. Phys. Chem. B, 112, 12899-12906, doi:10.1021/jp802806p, 2008b.

Davies, J. F. and Wilson, K. R.: Nanoscale interfacial gradients formed by the reactive uptake of $\mathrm{OH}$ radicals onto viscous aerosol surfaces, Chem. Sci., 6, 7020-7027, doi:10.1039/C5SC02326B, 2015.

Davies, J. F. and Wilson, K. R.: Raman spectroscopy of isotopic water diffusion in ultraviscous, glassy, and gel states in aerosol by use of optical tweezers, Anal. Chem., 88, 2361-2366, doi:10.1021/acs.analchem.5b04315, 2016.

DeCarlo, P. F., Dunlea, E. J., Kimmel, J. R., Aiken, A. C., Sueper, D., Crounse, J., Wennberg, P. O., Emmons, L., Shinozuka, Y., Clarke, A., Zhou, J., Tomlinson, J., Collins, D. R., Knapp, D., Weinheimer, A. J., Montzka, D. D., Campos, T., and Jimenez, J. L.: Fast airborne aerosol size and chemistry measurements above Mexico City and Central Mexico during the MILAGRO campaign, Atmos. Chem. Phys., 8, 4027-4048, doi:10.5194/acp-84027-2008, 2008.

Deschout, H., Hagman, J., Fransson, S., Jonasson, J., Rudemo, M., Lorén, N., and Braeckmans, K.: Straightforward FRAP for quantitative diffusion measurements with a laser 
scanning microscope, Opt. Express, 18, 22886-22905, doi:10.1364/OE.18.022886, 2010.

Edwards, D. A., Prausnitz, M. R., Langer, R., and Weaver, J. C.: Analysis of enhanced transdermal transport by skin electroporation, J. Control. Release, 34, 211-221, doi:10.1016/01683659(94)00132-E, 1995.

Ehlich, D. and Sillescu, H.: Tracer diffusion at the glass transition, Macromolecules, 23, 1600-1610, doi:10.1021/ma00208a008, 1990.

Essam, J. W.: Percolation theory, Reports Prog. Phys., 43, 833-912, doi:10.1088/0034-4885/43/7/001, 1980.

Fujara, F., Geil, B., Silescu, H., and Fleischer, G.: Translational and rotational diffusion in supercooled orthoterphenyl close to the glass-transition, Z. Phys. B Con. Mat., 88, 195-204, doi:10.1007/BF01323572, 1992.

Grayson, J. W., Zhang, Y., Mutzel, A., Renbaum-Wolff, L., Böge, O., Kamal, S., Herrmann, H., Martin, S. T., and Bertram, A. K.: Effect of varying experimental conditions on the viscosity of $\alpha$ pinene derived secondary organic material, Atmos. Chem. Phys., 16, 6027-6040, doi:10.5194/acp-16-6027-2016, 2016.

Greenspan, L.: Humidity fixed points of binary saturated aqueous solutions, J. Res. Natl. Bur. Stand. A, 81, 89-96, 1977.

Gržinić, G., Bartels-Rausch, T., Berkemeier, T., Türler, A., and Ammann, M.: Viscosity controls humidity dependence of $\mathrm{N}_{2} \mathrm{O}_{5}$ uptake to citric acid aerosol, Atmos. Chem. Phys., 15, 1361513625, doi:10.5194/acp-15-13615-2015, 2015.

Hatzigrigoriou, N. B., Papaspyrides, C. D., Joly, C., Pinte, J., and Dole, P.: Diffusion studies through fluorescence recovery after photobleaching in hydrated polyamides, Polym. Eng. Sci., 51, 532-541, doi:10.1002/pen.21843, 2011.

Hawkins, L. N., Russell, L. M., Covert, D. S., Quinn, P. K., and Bates, T. S.: Carboxylic acids, sulfates, and organosulfates in processed continental organic aerosol over the southeast Pacific Ocean during VOCALS-REx 2008, J. Geophys. Res., 115, D13201, doi:10.1029/2009JD013276, 2010.

Heald, C. L., Kroll, J. H., Jimenez, J. L., Docherty, K. S., Decarlo, P. F., Aiken, A. C., Chen, Q., Martin, S. T., Farmer, D. K., and Artaxo, P.: A simplified description of the evolution of organic aerosol composition in the atmosphere, Geophys. Res. Lett., 37, L08803, doi:10.1029/2010GL042737, 2010.

Heuberger, G. and Sillescu, H.: Size dependence of tracer diffusion in supercooled liquids, J. Phys. Chem., 100, 15255-15260, doi:10.1021/jp960968a, 1996.

Hildebrandt Ruiz, L., Paciga, A. L., Cerully, K. M., Nenes, A., Donahue, N. M., and Pandis, S. N.: Formation and aging of secondary organic aerosol from toluene: Changes in chemical composition, volatility, and hygroscopicity, Atmos. Chem. Phys., 15, 83018313, doi:10.5194/acp-15-8301-2015, 2015.

Hinks, M. L., Brady, M. V, Lignell, H., Song, M., Grayson, J. W., Bertram, A., Lin, P., Laskin, A., Laskin, J., and Nizkorodov, S. A.: Effect of viscosity on photodegradation rates in complex secondary organic aerosol materials, Phys. Chem. Chem. Phys., 18, 8785-8793, doi:10.1039/C5CP05226B, 2016.

Hosny, N. A., Fitzgerald, C., Tong, C., Kalberer, M., Kuimova, M. K., and Pope, F. D.: Fluorescent lifetime imaging of atmospheric aerosols: a direct probe of aerosol viscosity, Faraday Discuss., 165, 343-356, doi:10.1039/c3fd00041a, 2013.

Houle, F. A., Hinsberg, W. D., and Wilson, K. R.: Oxidation of a model alkane aerosol by $\mathrm{OH}$ radical: the emergent nature of reactive uptake, Phys. Chem. Chem. Phys., 17, 4412-4423, doi:10.1039/C4CP05093B, 2015.

Jimenez, J. L., Canagaratna, M. R., Donahue, N. M., Prevot, A. S. H., Zhang, Q., Kroll, J. H., DeCarlo, P. F., Allan, J. D., Coe, H., Ng, N. L., Aiken, A. C., Docherty, K. S., Ulbrich, I. M., Grieshop, A. P., Robinson, A. L., Duplissy, J., Smith, J. D., Wilson, K. R., Lanz, V. A., Hueglin, C., Sun, Y. L., Tian, J., Laaksonen, A., Raatikainen, T., Rautiainen, J., Vaattovaara, P., Ehn, M., Kumala, M., Tomlinson, J. M., Collins, D. R., Cubison, M. J., Dunlea, E. J., Huffman, J. A., Onasch, T. B., Alfarra, M. R., Williams, P. I., Bower, K., Kondo, Y., Schneider, J., Drewnick, F., Borrmann, S., Weimer, S., Demerjian, K., Salcedo, D., Cottrell, L., Griffin, R., Takami, A., Miyoshi, T., Hatakeyama, S., Shimono, A., Sun, J. Y., Zhang, Y. M., Dzepina, K., Kimmel, J. R., Sueper, D., Jayne, J. T., Herndon, S. C., Trimborn, A. M., Williams, L. R., Wood, E. C., Middlebrook, A. M., Kolb, C. E., Baltensperger, U., and Worsnop, D. R.: Evolution of organic aerosols in the atmosphere, Science, 326, 1525-1529, doi:10.1126/science.1180353, 2009.

Kidd, C., Perraud, V., Wingen, L. M., and Finlayson-Pitts, B. J.: Integrating phase and composition of secondary organic aerosol from the ozonolysis of $\alpha$-pinene, P. Natl. Acad. Sci. USA, 111, 7552-7557, doi:10.1073/pnas.1322558111, 2014.

Koop, T., Kapilashrami, A., Molina, L. T., and Molina, M. J.: Phase transitions of sea-salt/water mixtures at low temperatures: Implications for ozone chemistry in the polar marine boundary layer, J. Geophys. Res., 105, 26393, doi:10.1029/2000JD900413, 2000.

Koop, T., Bookhold, J., Shiraiwa, M., and Pöschl, U.: Glass transition and phase state of organic compounds: dependency on molecular properties and implications for secondary organic aerosols in the atmosphere, Phys. Chem. Chem. Phys., 13, 19238, doi:10.1039/c1cp22617g, 2011.

Kuwata, M. and Martin, S. T.: Phase of atmospheric secondary organic material affects its reactivity, P. Natl. Acad. Sci. USA, 109, 17354-17359, doi:10.1073/pnas.1209071109, 2012.

Li, Y. J., Liu, P., Gong, Z., Wang, Y., Bateman, A. P., Bergoend, C. Bertram, A. K., and Martin, S. T.: Chemical reactivity and liquid/nonliquid states of secondary organic material, Environ. Sci. Technol., 49, 13264-13274, doi:10.1021/acs.est.5b03392, 2015.

Lienhard, D. M., Huisman, A. J., Krieger, U. K., Rudich, Y., Marcolli, C., Luo, B. P., Bones, D. L., Reid, J. P., Lambe, A. T., Canagaratna, M. R., Davidovits, P., Onasch, T. B., Worsnop, D. R., Steimer, S. S., Koop, T., and Peter, T.: Viscous organic aerosol particles in the upper troposphere: Diffusivity-controlled water uptake and ice nucleation?, Atmos. Chem. Phys., 15, 1359913613, doi:10.5194/acp-15-13599-2015, 2015.

Lignell, H., Hinks, M. L., and Nizkorodov, S. A.: Exploring matrix effects on photochemistry of organic aerosols, P. Natl. Acad. Sci. USA, 111, 13780-13785, doi:10.1073/pnas.1322106111, 2014.

Longinotti, M. P. and Corti, H. R.: Diffusion of ferrocene methanol in super-cooled aqueous solutions using cylindrical microelectrodes, Electrochem. Commun., 9, 1444-1450, doi:10.1016/j.elecom.2007.02.003, 2007.

Lu, J. W., Rickards, A. M. J., Walker, J. S., Knox, K. J., Miles, R. E. H., Reid, J. P., and Signorell, R.: Timescales of water transport in viscous aerosol: measurements on sub-micron particles and dependence on conditioning history, Phys. Chem. Chem. Phys., 16, 9819-30, doi:10.1039/c3cp54233e, 2014. 
Marshall, F. H., Miles, R. E. H., Song, Y.-C., Ohm, P. B., Power, R. M., Reid, J. P., and Dutcher, C. S.: Diffusion and reactivity in ultraviscous aerosol and the correlation with particle viscosity, Chem. Sci., 7, 1298-1308, doi:10.1039/C5SC03223G, 2016.

Massoli, P., Lambe, A. T., Ahern, A. T., Williams, L. R., Ehn, M., Mikkilä, J., Canagaratna, M. R., Brune, W. H., Onasch, T. B., Jayne, J. T., Petäjä, T., Kulmala, M., Laaksonen, A., Kolb, C. E., Davidovits, P., and Worsnop, D. R.: Relationship between aerosol oxidation level and hygroscopic properties of laboratory generated secondary organic aerosol (SOA) particles, Geophys. Res. Lett., 37, L24801, doi:10.1029/2010GL045258, 2010.

Migliori, M., Gabriele, D., Di Sanzo, R., De Cindio, B., and Correra, S.: Viscosity of multicomponent solutions of simple and complex sugars in water, J. Chem. Eng. Data, 52, 1347-1353, doi:10.1021/je700062x, 2007.

Molinero, V., Çagin, T., and Goddard, W. A.: Sugar, water and free volume networks in concentrated sucrose solutions, Chem. Phys. Lett., 377, 469-474, doi:10.1016/S0009-2614(03)011709, 2003.

Mueller, F., Morisaki, T., Mazza, D., and McNally, J. G.: Minimizing the impact of photoswitching of fluorescent proteins on FRAP analysis, Biophys. J., 102, 1656-1665, doi:10.1016/j.bpj.2012.02.029, 2012.

Müller, C. and Loman, A.: Precise measurement of diffusion by multi-color dual-focus fluorescence correlation spectroscopy, EPL, 83, 46001, doi:10.1209/0295-5075/83/46001, 2008.

Murata, T., Lee, M. S., and Tanioka, A.: An application of percolation theory to the electrolyte penetration through porous waterswollen cellulose triacetate membrane, J. Colloid Interface Sci., 220, 250-254, doi:10.1006/jcis.1999.6529, 1999.

Mustafa, M. B., Tipton, D. L., Barkley, M. D., Russo, P. S., and Blum, F. D.: Dye diffusion in isotropic and liquid-crystalline aqueous (hydroxypropyl)cellulose, Macromolecules, 26, 370378, doi:10.1021/ma00054a017, 1993.

Ng, N. L., Canagaratna, M. R., Zhang, Q., Jimenez, J. L., Tian, J., Ulbrich, I. M., Kroll, J. H., Docherty, K. S., Chhabra, P. S., Bahreini, R., Murphy, S. M., Seinfeld, J. H., Hildebrandt, L., Donahue, N. M., Decarlo, P. F., Lanz, V. A., Prévôt, A. S. H., Dinar, E., Rudich, Y., and Worsnop, D. R.: Organic aerosol components observed in Northern Hemispheric datasets from Aerosol Mass Spectrometry, Atmos. Chem. Phys., 10, 46254641, doi:10.5194/acp-10-4625-2010, 2010.

Pajunoja, A., Malila, J., Hao, L., Joutsensaari, J., Lehtinen, K. E. J., and Virtanen, A.: Estimating the viscosity range of SOA particles based on their coalescence time, Aerosol Sci. Technol., 48, i-v, doi:10.1080/02786826.2013.870325, 2014.

Pajunoja, A., Lambe, A. T., Hakala, J., Rastak, N., Cummings, M. J., Brogan, J. F., Hao, L., Paramonov, M., Hong, J., Prisle, N. L., Malila, J., Romakkaniemi, S., Lehtinen, K. E. J., Laaksonen, A., Kulmala, M., Massoli, P., Onasch, T. B., Donahue, N. M., Riipinen, I., Davidovits, P., Worsnop, D. R., Petäjä, T., and Virtanen, A.: Adsorptive uptake of water by semisolid secondary organic aerosols, Geophys. Res. Lett., 42, 3063-3068, doi:10.1002/2015GL063142, 2015.

Pang, X.-F.: Water: molecular structure and properties, Hackensack, New Jersey, NJ, 2014.

Pant, A., Fok, A., Parsons, M. T., Mak, J., and Bertram, A. K.: Deliquescence and crystallization of ammonium sulfate-glutaric acid and sodium chloride-glutaric acid particles, Geophys. Res. Lett., 31, L12111, doi:10.1029/2004GL020025, 2004.

Pant, A., Parsons, M. T., and Bertram, A. K.: Crystallization of aqueous ammonium sulfate particles internally mixed with soot and kaolinite: Crystallization relative humidities and nucleation rates, J. Phys. Chem. A, 110, 8701-8709, doi:10.1021/jp060985s, 2006.

Perraud, V., Bruns, E. a, Ezell, M. J., Johnson, S. N., Yu, Y., Alexander, M. L., Zelenyuk, A., Imre, D., Chang, W. L., Dabdub, D., Pankow, J. F., and Finlayson-Pitts, B. J.: Nonequilibrium atmospheric secondary organic aerosol formation and growth, P. Natl. Acad. Sci. USA, 109, 2836-2841, doi:10.1073/pnas.1119909109, 2012.

Power, R. M., Simpson, S. H., Reid, J. P., and Hudson, A. J.: The transition from liquid to solid-like behaviour in ultrahigh viscosity aerosol particles, Chem. Sci., 4, 2597-2604, doi:10.1039/C3SC50682G, 2013.

Price, H. C., Murray, B. J., Mattsson, J., O’Sullivan, D., Wilson, T. W., Baustian, K. J., and Benning, L. G.: Quantifying water diffusion in high-viscosity and glassy aqueous solutions using a Raman isotope tracer method, Atmos. Chem. Phys., 14, 38173830, doi:10.5194/acp-14-3817-2014, 2014.

Price, H. C., Mattsson, J., Zhang, Y., Bertram, A. K., Davies, J. F., Grayson, J. W., Martin, S. T., O’Sullivan, D., Reid, J. P., Rickards, A. M. J., and Murray, B. J.: Water diffusion in atmospherically relevant $\alpha$-pinene secondary organic material, Chem. Sci., 6, 4876-4883, doi:10.1039/C5SC00685F, 2015.

Price, H. C., Mattsson, J., and Murray, B. J.: Sucrose diffusion in aqueous solution, Phys. Chem. Chem. Phys., 18, 19207-19216, doi:10.1039/C6CP03238A, 2016.

Quintas, M., Brandão, T. R. S., Silva, C. L. M., and Cunha, R. L.: Rheology of supersaturated sucrose solutions, J. Food Eng., 77, 844-852, doi:10.1016/j.jfoodeng.2005.08.011, 2006.

Rampp, M., Buttersack, C., and Luedemann, H. D.: c,T-dependence of the viscosity and the self-diffusion coefficients in some aqueous carbohydrate solutions, Carbohydr. Res., 328, 561-572, doi:10.1016/S0008-6215(00)00141-5, 2000.

Renbaum-Wolff, L., Grayson, J. W., and Bertram, A. K.: Technical Note: New methodology for measuring viscosities in small volumes characteristic of environmental chamber particle samples, Atmos. Chem. Phys., 13, 791-802, doi:10.5194/acp-13791-2013, 2013a.

Renbaum-Wolff, L., Grayson, J. W., Bateman, A. P., Kuwata, M., Sellier, M., Murray, B. J., Shilling, J. E., Martin, S. T., and Bertram, A. K.: Viscosity of $\alpha$-pinene secondary organic material and implications for particle growth and reactivity, P. Natl. Acad. Sci. USA, 110, 8014-8019, doi:10.1073/pnas.1219548110, 2013b.

Robinson, E. S., Saleh, R., and Donahue, N. M.: Organic aerosol mixing observed by single-particle mass spectrometry, J. Phys. Chem. A, 117, 13935-13945, doi:10.1021/jp405789t, 2013.

Rossler, E.: Indications for a change of diffusion mechanism in supercooled liquids, Phys. Rev. Lett., 65, 1595-1598, doi:10.1103/PhysRevLett.65.1595, 1990.

Rossler, E. and Sokolov, A. P.: The dynamics of strong and fragile glass formers, Chem. Geol., 128, 143-153, doi:10.1016/00092541(95)00169-7, 1996.

Saleh, R., Donahue, N. M., and Robinson, A. L.: Time scales for gas-particle partitioning equilibration of secondary organic 
aerosol formed from alpha-pinene ozonolysis, Environ. Sci. Technol., 47, 5588-5594, doi:10.1021/es400078d, 2013.

Schill, G. P., O., D. H. D., and Tolbert, M. A.: Heterogeneous ice nucleation on simulated secondary organic aerosol, Environ. Sci. Technol., 48, 1675-1692, doi:10.1021/es4046428, 2014.

Seksek, O., Biwersi, J., and Verkman, A. S.: Translational diffusion of macromolecule-sized solutes in cytoplasm and nucleus, J. Cell Biol., 138, 131-142, doi:10.1083/jcb.138.1.131, 1997.

Shiraiwa, M., Ammann, M., Koop, T., and Pöschl, U.: Gas uptake and chemical aging of semisolid organic aerosol particles, P. Natl. Acad. Sci. USA, 108, 11003-11008, doi:10.1073/pnas.1103045108, 2011.

Sinnecker, D., Voigt, P., Hellwig, N., and Schaefer, M.: Reversible photobleaching of enhanced green fluorescent proteins, Biochemistry, 44, 7085-7094, doi:10.1021/bi047881x, 2005.

Smith, L. M., McConnell, H. M., Smith Baron, A., and Parce, J. W.: Pattern photobleaching of fluorescent lipid vesicles using polarized laser light, Biophys. J., 33, 139-146, doi:10.1016/S00063495(81)84877-1, 1981

Song, M., Liu, P. F., Hanna, S. J., Li, Y. J., Martin, S. T., and Bertram, A. K.: Relative humidity-dependent viscosities of isoprene-derived secondary organic material and atmospheric implications for isoprene-dominant forests, Atmos. Chem. Phys., 15, 5145-5159, doi:10.5194/acp-15-5145-2015, 2015.

Song, M., Liu, P. F., Hanna, S. J., Zaveri, R. A., Potter, K., You, Y., Martin, S. T., and Bertram, A. K.: Relative humiditydependent viscosity of secondary organic material from toluene photo-oxidation and possible implications for organic particulate matter over megacities, Atmos. Chem. Phys., 16, 8817-8830, doi:10.5194/acp-16-8817-2016, 2016.

Takahama, S., Schwartz, R. E., Russell, L. M., MacDonald, A. M., Sharma, S., and Leaitch, W. R.: Organic functional groups in aerosol particles from burning and non-burning forest emissions at a high-elevation mountain site, Atmos. Chem. Phys., 11, 6367-6386, doi:10.5194/acp-11-6367-2011, 2011.

Tamba, Y., Ariyama, H., Levadny, V., and Yamazaki, M.: Kinetic pathway of antimicrobial peptide magainin 2-induced pore formation in lipid membranes, J. Phys. Chem. B, 114, 1201812026, doi:10.1021/jp104527y, 2010.

Telis, V. R. N., Telis-Romero, J., Mazzotti, H. B., and Gabas, A. L.: Viscosity of aqueous carbohydrate solutions at different temperatures and concentrations, Int. J. Food Prop., 10, 185-195, doi:10.1080/10942910600673636, 2007.

Wang, B., Lambe, A. T., Massoli, P., Onasch, T. B., Davidovits, P., Worsnop, D. R., and Knopf, D. A.: The deposition ice nucleation and immersion freezing potential of amorphous secondary organic aerosol: Pathways for ice and mixedphase cloud formation, J. Geophys. Res.-Atmos., 117, 1-12, doi:10.1029/2012JD018063, 2012.

Wang, B., O’brien, R. E., Kelly, S. T., Shilling, J. E., Moffet, R. C., Gilles, M. K., and Laskin, A.: Reactivity of liquid and semisolid secondary organic carbon with chloride and nitrate in atmospheric aerosols, J. Phys. Chem. A, 119, 4498-4508, doi:10.1021/jp510336q, 2015.
Wheeler, M. J. and Bertram, A. K.: Deposition nucleation on mineral dust particles: A case against classical nucleation theory with the assumption of a single contact angle, Atmos. Chem. Phys., 12, 1189-1201, doi:10.5194/acp-12-1189-2012, 2012.

Wilson, T. W., Murray, B. J., Wagner, R., Möhler, O., Saathoff, H., Schnaiter, M., Skrotzki, J., Price, H. C., Malkin, T. L., Dobbie, S., and Al-Jumur, S. M. R. K.: Glassy aerosols with a range of compositions nucleate ice heterogeneously at cirrus temperatures, Atmos. Chem. Phys., 12, 8611-8632, doi:10.5194/acp-128611-2012, 2012.

Wong, J. P. S., Zhou, S., and Abbatt, J. P. D.: Changes in secondary organic aerosol composition and mass due to photolysis: Relative humidity dependence, J. Phys. Chem. A, 119, 4309-4316, doi:10.1021/jp506898c, 2015.

Yatavelli, R. L. N., Stark, H., Thompson, S. L., Kimmel, J. R., Cubison, M. J., Day, D. A., Campuzano-Jost, P., Palm, B. B., Hodzic, A., Thornton, J. A., Jayne, J. T., Worsnop, D. R., and Jimenez, J. L.: Semicontinuous measurements of gas-particle partitioning of organic acids in a ponderosa pine forest using a MOVI-HRToFCIMS, Atmos. Chem. Phys., 14, 1527-1546, doi:10.5194/acp14-1527-2014, 2014.

Zhang, Q., Jimenez, J. L., Canagaratna, M. R., Allan, J. D., Coe, H., Ulbrich, I., Alfarra, M. R., Takami, A., Middlebrook, A. M., Sun, Y. L., Dzepina, K., Dunlea, E., Docherty, K., DeCarlo, P. F., Salcedo, D., Onasch, T., Jayne, J. T., Miyoshi, T., Shimono, A., Hatakeyama, S., Takegawa, N., Kondo, Y., Schneider, J., Drewnick, F., Borrmann, S., Weimer, S., Demerjian, K., Williams, P., Bower, K., Bahreini, R., Cottrell, L., Griffin, R. J., Rautiainen, J., Sun, J. Y., Zhang, Y. M., and Worsnop, D. R.: Ubiquity and dominance of oxygenated species in organic aerosols in anthropogenically-influenced Northern Hemisphere midlatitudes, Geophys. Res. Lett., 34, L13801, doi:10.1029/2007GL029979, 2007.

Zhang, X., McVay, R. C., Huang, D. D., Dalleska, N. F., Aumont, B., Flagan, R. C., and Seinfeld, J. H.: Formation and evolution of molecular products in $\alpha$-pinene secondary organic aerosol, P. Natl. Acad. Sci. USA, 112, 14168-14173, doi:10.1073/pnas.1517742112, 2015.

Zhou, S., Lee, A. K. Y., McWhinney, R. D., and Abbatt, J. P. D.: Burial effects of organic coatings on the heterogeneous reactivity of particle-borne benzo[a]pyrene (BaP) toward ozone, J. Phys. Chem. A, 116, 7050-7056, doi:10.1021/jp3030705, 2012.

Zobrist, B., Soonsin, V., Luo, B. P., Krieger, U. K., Marcolli, C., Peter, T., and Koop, T.: Ultra-slow water diffusion in aqueous sucrose glasses, Phys. Chem. Chem. Phys., 13, 3514-3526, doi:10.1039/c0cp01273d, 2011. 